\title{
Assessment of Tumor Take Inhibitory Activity of Ethanolic Leaf Extract of Piper betle L. in Mice
}

\author{
Deepa Iyer $^{1}{ }^{(\mathbb{D})}$, Nafeesa Siddiqui ${ }^{1}$, Umesh Kumar Patil ${ }^{2, *}$ (D) \\ 1 Quality Assurance Laboratory, Madhya Pradesh Council of Science and Technology,Vigyan Bhawan, Bhopal, 462003, \\ M.P., India \\ 2 Department of Pharmaceutical Sciences, Dr. Harisingh Gour Vishwavidyalaya, Sagar - 470003, (M.P.) India \\ * Correspondence: umeshpatil29@gmail.com;
}

Scopus Author ID 26639794300

Received: 22.12.2020; Revised: 27.01.2021; Accepted: 31.01.2021; Published: 8.02.2021

\begin{abstract}
The present study was undertaken to explore the tumor take inhibitory effects of ethanolic extract of Piper betle in rodents. Tumor takes inhibitory activity was investigated in hybrid mice (of C57BL strain + Swiss albino strain). Preventive group animals were injected daily with the extract at a dose of $50 \mathrm{mg} / \mathrm{kg}$ body weight, i.p. for 10 consecutive days. The animals were observed to grow tumors after injection of B16F10 melanoma cells into mice's dorsal skin. Pretreatment with the extract and showed delays in tumor growth by increasing the volume doubling time, VDT $(\mathrm{p}<0.01)$, growth delay, GD ( $\mathrm{p}<0.01)$, and mean survival time, MST ( $<<0.001)$. Tumor regression studies showed a regression response for tumor growth in vivo of murine mouse melanoma tumor cell lines, demonstrated by increasing the VDT and GD.
\end{abstract}

Keywords: Piper betle; B16F10 melanoma cells; volume doubling time; growth delay, mean survival time, tumor regression.

(C) 2021 by the authors. This article is an open-access article distributed under the terms and conditions of the Creative Commons Attribution (CC BY) license (https://creativecommons.org/licenses/by/4.0/).

\section{Introduction}

A balance is usually maintained between cell renewal and cell death in most organs and tissues in a mature animal. The various types of mature cells in the body have a given life span; as these cells die, new cells are generated by the proliferation and differentiation of various types of stem cells [1]. Under abnormal conditions, the cells give rise to clones of cells that can expand to a considerable size, producing a tumor or neoplasm. Tumors are caused by mutations in DNA of cells [2].

Current major cancer management treatments include surgery, cytotoxic chemotherapy, targeted therapy, radiation therapy, endocrine therapy, and immunotherapy [3]. During cancer progression, tumors become highly heterogeneous, creating a mixed population of cells characterized by different molecular features and diverse responsivity to therapies [4]. Nanoparticles can be exploited for different applications, ranging from diagnosis to therapy. They are maintaining adjuvant therapy with curative intent for solid tumors $[5,6]$. Tumors from patients showing sustained treatment response predominately demonstrate a $\mathrm{T}$ cell-inflamed tumor microenvironment before, or early on, treatment [7-10]. Anticancer plants were majorly from the families Bignoniaceae (7\%), Caricaceae (7\%), Fabaceae (7\%), Moraceae (7\%), and Rutaceae (7\%). Most species occur in the wild (52\%), though some are cultivated $(48 \%)[11,12]$. 
Piper betle L. (Piperaceae) is commonly known as Paan. In India, it is used as a flavoring agent in curries and chutneys. The leaves of the curry tree are used as an important herb in the medical science of Ayurveda [13].

The leaves, roots, and seeds are all used for medicinal purposes in Asia. The leaves are anthelmintic, antibacterial, antifungal, antiseptic, aphrodisiac, astringent, carminative, expectorant, laxative, gastroprotective, sialagogue, stimulant, stomachic, and tonic [14]. Leaf preparations and the leaf sap are applied to wounds, ulcers, boils, and bruises. Heated leaves are applied as a poultice on the chest against cough, asthma, and abdomen to relieve constipation. The leaves are also used to treat nosebleed, ulcerated noses, gums, and mucous membranes, while the extract from the leaves is applied for wounds in the ears and as an infusion for the eye [15].

A decoction of the leaves is used for bathing a woman after childbirth or is drunk to lessen an unpleasant body odor. The essential oil obtained from the leaves is antibacterial and antifungal.

It has shown anthelmintic activity against tapeworms and hookworms. It has been used to treat affections of the mucous membrane of the nose, throat, and respiratory organs $[14,15]$.

This study provides scientific evidence for applying the traditional medicinal plant, Piper betle, in the retardation of tumor growth.

\section{Materials and Methods}

\subsection{Plant material.}

The leaves of Piper Betle L. were collected from Bhopal (M.P.), India, and were identified and authenticated by Dr. Zia ul Hassan, Assistant professor, Department of Botany, Saifia College of Science \& Education, Bhopal. A voucher specimen No.175/Bot/Safia/2010 is deposited in the botany department's herbarium.

\subsection{Extraction.}

The dried drug (800 g) was coarsely powdered and then exhaustively extracted with $90 \%$ ethanol in Soxhlet apparatus. The ethanolic extract so obtained was freed of solvent under vacuum to get $95 \mathrm{~g}$ (12\% yield) of dark greenish-brown mass.

\subsection{Screening for tumor take inhibitory activity.}

\subsubsection{Animal model.}

The hybrid mice (of C57BL strain + Swiss albino strain) were selected from a random breed colony maintained in the animal house of the Research Department of Jawaharlal Nehru Cancer Hospital, Bhopal, M.P., India. The mice were housed in polypropylene cages maintained under controlled conditions. The animals were fed standard feed (formula obtained from Cancer Research Institute, Mumbai, India) and acidified water ad libitum. Mice of either sex, 6 - 8 weeks old and weighing 20-25 g, were selected from the above colony for the experiments.

2.3.2. Tumor model: B16F10 melanoma.

B16F10 melanoma originally obtained from National Cell Centre, Pune, India, was maintained by serial transplantation in a C57BL mouse. 


\subsubsection{Tumor propagation.}

Tumor-bearing mouse was sacrificed by cervical dislocation, and the whole animal was dipped in $70 \%$ alcohol. The tumor was excised to single-cell suspension by mechanical dispersion. The cell suspension was filtered through a $45 \mu$ nylon mesh. The single-cell suspension was then passed through different gauze size needle. The cell suspension was again passed through nylon mesh to remove the clumps of cells.

\subsubsection{Methodology.}

The animals were divided into two groups. Group I served as a control, and Group II served as a test group. Group II was injected daily with the ethanolic leaf extract of Piper betle $50 \mathrm{mg} / \mathrm{kg}$ body wt. i.p. for 10 consecutive days. Three weeks after the last injection of the extract, the animals were injected with $5 \times 10^{5}$ viable B16F10 melanoma cells into the dorsal skin. The animals were observed for the growth of the tumor. Volume doubling time and Growth delay were calculated [16].

\subsubsection{Tumor growth kinetics.}

The tumor size was measured every alternate day, and the tumor volume was calculated. Tumor diameters are measured with digital calipers, and the tumor volume in $\mathrm{mm}^{3}$ is calculated by the formula: volume $=(\text { width })^{2} \mathrm{x}$ length $/ 2$.

Tumor growth response was assessed from the following parameters:

Volume doubling time (VDT):The time in days for the size of the tumor to reach double the treatment volume.

Growth delay (GD): Tumor growth delay (the increase in time required for the treated tumor to reach $1000 \mathrm{~mm} 3$ ) has been used to assess the response of the drug.

\subsubsection{Statistical analysis.}

Statistical evaluation of the data was done by Student' $t$ ' test. (Graph PAD Instat software, Kyplot). A value of $\mathrm{p}<0.05$ was considered to be significant.

\section{Results and Discussion}

Pretreatment with the test extract showed a delay tumor growth, demonstrated by the growth curve, by increasing the Volume Doubling Time (VDT) and Growth Delay (GD) (Figure 1).

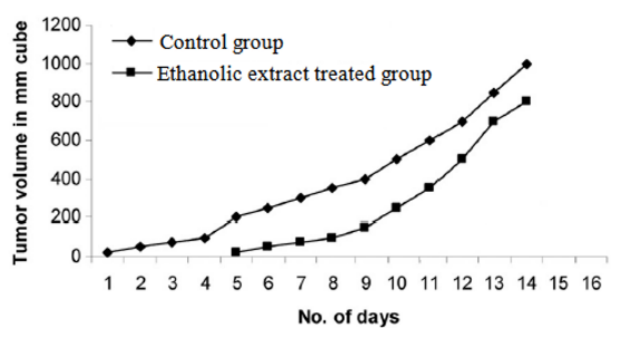

Figure 1. Growth curve.

\subsection{Silent period.}

The silent period (i.e., time is taken for palpable growth) for the control group was found to be 1 day, while in the case of the ethanolic extract-treated group, it was found to be 5 days respectively, which was very significant $(\mathrm{p}<0.001)$. 


\subsection{Volume doubling time.}

The volume doubling time observed for ethanolic extract was found to be 3 days that were significant $(\mathrm{p}<0.01)$ compared to control.

\subsection{Growth delay.}

The GD was 2 days in the ethanolic extract-treated group, which was significant $(\mathrm{p}<0.01)$ compared to the control (Table 1).

Table 1. Response of B16F10 mouse melanoma to the treatment with ethanolic extract at the dose of $50 \mathrm{mg} / \mathrm{kg}$ : Silent period, VDT, GD, and MST.

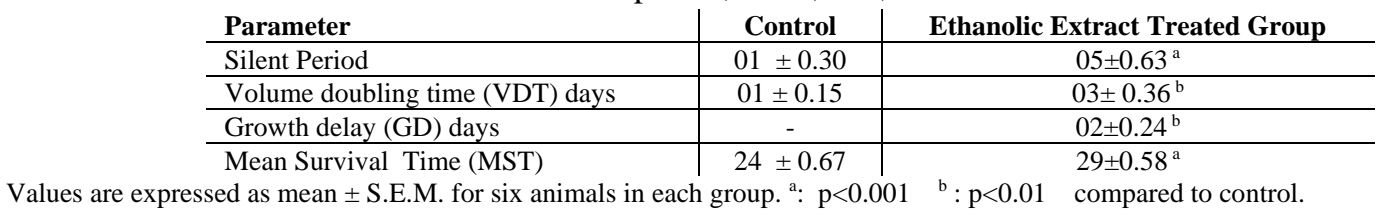

\subsection{Mean survival time.}

The maximum survival time was observed to be 24 days for the control group. The MST observed for ethanolic extract-treated groups was 29 days, which was 5 days more than the control group. Comparisons between the control group's MST with test drugs treated group was very significant $(\mathrm{p}<0.001)$. Tumor regression studies showed a regression response for tumor growth in vivo of murine mouse melanoma. The treatment produced a delay in tumor growth, as demonstrated by increasing the VDT and GD. Indications are available that this plant has got antioxidant properties. Oxidative stress has been implicated in numerous pathophysiological conditions, including cancer.

Research on herbal medicines is gaining ground. The demand to use natural products to treat various disorders is increasing worldwide. Tumor regression studies showed a regression response for tumor growth in vivo of murine mouse melanoma. Tumor regression was related to the immune-stimulatory properties of the antibody [16, 17]. The treatment produced a delay in tumor growth, as demonstrated by increasing the VDT and GD. Indications are available that this plant has got antioxidant properties. Oxidative stress has been implicated in numerous pathophysiological conditions, including cancer. Prevention of oxidative damage can be employed as one of the ways in tumor regression.

\section{Conclusions}

Treatment with Piper betle leaf extract showed a tumor regression response. The present investigations may be quite useful as this drug is highly valued in the traditional system of medicine.

\section{Funding}

This research received no external funding.

\section{Acknowledgments}

The authors are thankful to the Jawaharlal Nehru Cancer Research Center, Bhopal, for providing the necessary laboratory facilities to carry out this research work and the 
Sophisticated Instrumentation Center (SIC), Dr. Harisingh Gour Vishwavidyalaya, Sagar for sophisticated instrumentation facilities supported under DST-PURSE (II).

\section{Conflicts of Interest}

The authors declare no conflict of interest.

\section{References}

1. Thomlinson, R.H.; Gray, L.H. The histological structure of some human lung cancers and the possible implications for radiotherapy. Br. J. Cancer 1955, 9, 539-549, https://doi.org/10.1038/bjc.1955.55.

2. Barker, J.L.; Motague, E.D.; Peters L.J. Clinical experience with irradiation of inflammatory carcinoma of the breast with and without elective chemotherapy. Cancer 1980, 45, 625-629, https://doi.org/10.1002/10970142(19800215)45:4<625::AID-CNCR2820450402>3.0.CO;2-V.

3. Xuan,W.; Haiyun, Z.; Xiaozhuo, C. Drug resistance and combating drug resistance in cancer. Cancer Drug Resist. 2019, 2, 141-160, https://doi.org/10.20517/cdr.2019.10.

4. Martinelli, C.; Pucci, C.; Ciofani, G. Innovative approaches for cancer treatment: current perspectives and new challenges. E Cancer Med. Sci. 2019, 13, https://doi.org/10.3332/ecancer.2019.961.

5. Martinelli, C.; Pucci, C.; Ciofani, G. Nanostructured carriers as innovative tools for cancer diagnosis and therapy. APL Bioeng. 2019, 3, https://doi.org/10.1063/1.5079943.

6. Moujaess, E.; Kourie, H.; Ghosn, M. Cancer patients and research during COVID-19 pandemic: A systematic review of current evidence. Crit. Rev. Oncol. Hematol. 2020, 150, https://doi.org/10.1016/j.critrevonc.2020.102972.

7. Labadie, B.W.; Bao, R.; Luke, J.J. Reimagining IDO pathway inhibition in cancer immunotherapy via downstream focus on the tryptophan-kynurenine-aryl hydrocarbon axis. Clin. Cancer Res. 2019, 25, 14621471, https://doi.org/10.1158/1078-0432.CCR-18-2882.

8. Shi, J.; Chen, C.; Ju, R.; Wang, Q.; Li, J.; Guo, L.; Ye, C.; Zhang, D. Carboxyamidotriazole combined with IDO1-Kyn-AhR pathway inhibitors profoundly enhances cancer immunotherapy. Journal for ImmunoTherapy of Cancer 2019, 7, https://doi.org/10.1186/s40425-019-0725-7.

9. Bartok, O.; Pataskar, A.; Nagel, R.; Laos, M.; Goldfarb, E.; Hayoun, D.; Levy, R.; Körner, P.-R.; Kreuger, I.Z.M.; Champagne, J.; Zaal, E.A.; Bleijerveld, O.B.; Huang, X.; Kenski, J.; Wargo, J.; Brandis, A.; Levin, Y.; Mizrahi, O.; Alon, M.; Lebon, S.; Yang, W.; Nielsen, M.M.; Stern-Ginossar, N.; Altelaar, M.; Berkers, C.R.; Geiger, T.; Peeper, D.S.; Olweus, J.; Samuels, Y.; Agami, R. Anti-tumour immunity induces aberrant peptide presentation in melanoma. Nature 2020, in press, https://doi.org/10.1038/s41586-020-03054-1.

10. Cheng, B.; Xiong, S.; Li, C.; Liang, H.; Zhao, Y.; Li, J.; Shi, J.; Ou, L.; Chen, Z.; Liang, P.; Liang, W.; He, J.J.J.O.T.D. An annual review of the remarkable advances in lung cancer clinical research in 2019. J. Thorac. Dis. 2020, 12, 1056-1069. https://doi.org/10.21037/jtd.2020.03.11.

11. Lang, S.J.; Schmiech, M.; Hafner, S.; Paetz, C.; Steinborn, C.; Huber, R.; Gaafary, M.E.; Werner, K.; Schmidt, C.Q.; Syrovets, T.; Simmet, T. Antitumor activity of an Artemisia annua herbal preparation and identification of active ingredients. Phytomedicine : international journal of phytotherapy and phytopharmacology 2019, 62, https://doi.org/10.1016/j.phymed.2019.152962.

12. Omara, T.; Kiprop, A.K.; Ramkat, R.C.; Cherutoi, J.; Kagoya, S.; Moraa Nyangena, D.; Azeze Tebo, T.; Nteziyaremye, P.; Nyambura Karanja, L.; Jepchirchir, A.; Maiyo, A.; Jematia Kiptui, B.; Mbabazi, I.; Kiwanuka Nakiguli, C.; Nakabuye, B.V.; Chepkemoi Koske, M. Medicinal Plants Used in Traditional Management of Cancer in Uganda: A Review of Ethnobotanical Surveys, Phytochemistry, and Anticancer Studies. Evidence-Based Complementary and Alternative Medicine 2020, 2020,https://doi.org/10.1155/2020/3529081.

13. Gogtay, N.J.; Bhatt, H.A.; Dalvi, S.S.; Kshirsagar, N.A. The Use and Safety of Non-Allopathic Indian Medicines. Drug Safety 2002, 25, 1005-1019, https://doi.org/10.2165/00002018-200225140-00003.

14. Ching, L.; Rowa, M.; Hob, J.C. The antimicrobial activity, mosquito larvicidal activity, antioxidant property and tyrosinase inhibition of Piper betle. J. Chi. Chem. Society 2009, 56, 653-658, https://doi.org/10.1002/jccs.200900097.

15. Arawwala, L.; Arambewela, L.; Ratnasooriya, W. Gastroprotective effect of Piper betle L. J. Ayur. Integr. Med. 2014, 5, 38-42.

16. Uma Devi, P.; Guruprasad, K. Influence of clamping-induced ischemia and reperfusion on the response of a mouse melanoma to radiation and hyperthermia Int. J. Hyperthermia 2001, 17, 357-367.

17. Hardy, B.; Kovjazin, R.; Raiter, A.; Ganor, N.; Novogrodsky, A. A lymphocyte-activating monoclonal antibody induces regression of human tumors in severe combined immunodeficient mice. Immunol. 1997, 94, 5756-5760, https://doi.org/10.1073/pnas.94.11.5756. 